\title{
CONTROL LAW SYNTHESIS FOR VERTICAL FIN BUFFETING ALLEVIATION USING STRAIN ACTUATION
}

\author{
F. Nitzsche* and D. G. Zimcik ${ }^{*}$ \\ National Research Council of Canada \\ Institute for Aerospace Research \\ Ottawa, Ontario, Canada, K1A 0R6 \\ T. G. Ryall ${ }^{\$ \$}$ \\ Aeronautical and Maritime Research Laboratory \\ P.O. Box 4331, Victoria 3001, Australia \\ R. W. Moses ${ }^{\text {II }}$ \\ NASA Langley Research Center \\ Hampton, VA, 23681-2199, USA \\ D. A. Henderson ${ }^{\#}$ \\ Air Force Research Laboratory \\ Wright-Patterson AFB \\ Dayton, OH, 45433-7006, USA
}

\begin{abstract}
$\underline{\text { Abstract }}$
In the present investigation, the results obtained during the ground test of a closed-loop control system conducted on a full-scale fighter to attenuate vertical fin buffeting response using strain actuation are presented. Two groups of actuators consisting of piezoelectric elements distributed over the structure were designed to achieve authority over the first and second modes of the vertical fin. The control laws were synthesized using the Linear Quadratic Gaussian (LQG) method for a time-invariant control system. Three different pairs of sensors including strain gauges and accelerometers at different locations were used to close the feedback loop. The results demonstrated that measurable reductions in the root-mean-square (RMS) values of the fin dynamic response identified by the strain transducer at the critical point for fatigue at the root were achieved under the most severe buffet condition. For less severe buffet conditions, reductions of up to $58 \%$ were achieved.
\end{abstract}

\section{$\underline{\text { Nomenclature }}$}

$G \quad$ open-loop transfer function matrix

$G_{c} \quad$ closed-loop transfer function matrix

$\begin{array}{ll}G_{u} & \text { controller transfer function matrix } \\ H & \text { feedback transfer function matrix } \\ u & \text { vector of control variables } \\ v & \text { transducer noise } \\ w & \text { buffet disturbance } \\ y & \text { feedback vector } \\ y_{v} & \text { noisy feedback vector } \\ z & \text { vector of performance metrics }\end{array}$

Introduction

It is difficult to predict buffet loads during the design stage of an aircraft. One such example is the F/A-18 known in Canada as the CF-188. This twin-tail aircraft is often subjected to high-intensity buffet loads that produce accelerations in excess of $450 \mathrm{~g}$ at the tip of the vertical fin during maneuvers at high angles of attack. An initial approach to minimize the problem included the introduction of a leading edge extension (LEX) fence. This fence has been added to the aircraft wing root to reduce buffeting by generating additional vortices that interact with the vertical tail and assure airflow attachment to the surface. However, at very high angles of attack, the vortices generated by the

\footnotetext{
* Senior Research Officer. Senior Member AIAA.

${ }^{\ddagger}$ Head, Aeroacoustics and Structural Dynamics Group. Senior Member AIAA.

$\$$ Principal Research Scientist.

II Aerospace Technologist. Aeroelasticity Branch. Member AIAA.

\#Aerospace Engineer.

Copyright (C) National Research Council of Canada.

Published by the American Institute of Aeronautics and Astronautics, Inc. with permission.
} 
LEX fence break down before reaching the tail, generating an even more turbulent wake. Previous investigations were able to demonstrate that the first and the second natural modes of the vertical fin at approximately $17 \mathrm{~Hz}$ (bending) and $43 \mathrm{~Hz}$ (coupled bending torsion), respectively contribute most significantly to the buffeting phenomenon. ${ }^{1-4}$ The resulting loads substantially contribute to the fatigue of the tail structure, increasing the maintenance costs of the fighter.

This problem is of particular concern for those countries within The Technical Co-operation Program, (TTCP) that include the F/A-18 in their fleets. The TTCP is a program of technical collaboration and data exchange among five nations: Canada, the United States, Australia, United Kingdom and New Zealand. Of these participants, three countries, namely Canada, the United States, and Australia have initiated a collaborative research program aimed at solutions to the problem. The overall approach of the program is to develop an active control system that includes strain actuation using piezoelectric elements. However, the ability of the piezoelectric actuators to achieve control authority under the large aerodynamic buffet loads in a full-scaled aircraft needs to be demonstrated. Ground tests were planned under the TTCP program with the objective of evaluating the performance of the "smart structures" solution. In this program, Australia contributed the test rig; Canada offered the input data information in the form of representative buffet time sequences measured in flight, and the United States provided the control system hardware. All TTCP partners contributed to the software design with unique control strategies.

The closed-loop tests of the proposed active control system were carried out in the International Follow-on Structural Test Project (IFOSTP) rig in Melbourne, Australia, in the period between January 12 and February 13, 1998. These tests represented an important milestone on the development of adaptive structures systems with application to aeroelastic problems because they were the first tests performed on a full-scale airframe to achieve buffeting alleviation. The objectives of the ground test were: (1) to demonstrate active buffeting alleviation of a full-scale aircraft; (2) to measure vibration level reductions at different points on the tail, most significantly, at the critical points situated at the fin root where fatigue cracks have been spotted due to high bending stress; (3) to demonstrate piezoelectric control authority at full buffet loads; and (4) to measure vibration reduction at different flight conditions demonstrating the controller robustness under different excitation loads. Open-loop tests to identify the dynamics of the structure and its control hardware were performed in September 1997.
The present work reports the control design strategy and the results obtained by the TTCP partners in the closed-loop tests. The hardware was configured to accept a MIMO feedback control system with up to two inputs (consisting of a choice among several strain gauges and accelerometers distributed over the surface of the vertical fin to measure the performance of the system), and two outputs that drive two groups of piezoelectric actuators attached to both sides of the structure skin. The actuators on opposite sides of the fin were phased locked by $180^{\circ}$ as would be the case in local bending.

\section{$\underline{\text { Smart Structures Solution }}$}

Some earlier studies incorporating active control techniques to suppress aerodynamic buffeting focused on the classical aeroservoelastic approach, where the rudder was the actuation device. ${ }^{5}$ In still other studies control of the vortices has been attempted by steady state blowing though ports in the leading edge of the wing and lead edge extension with mixed results. ${ }^{8}$ Several fixes to the problem are already incorporated on both the F/A-18 and the F-15 that use a leading edge extension (LEX) fence that affects the vortex burst point or an exo-skin patch that changes the stiffness of the vertical tail moving the resonant frequency response away from the excitation frequency, respectively However, the frequency bandwidth of these hydraulically driven control surfaces is not sufficient to reduce buffeting in the higher modes. Therefore, adaptive structures provide an attractive solution to the problem. $^{6-7}$ Besides having higher frequency bandwidths, piezoelectric actuators allow for the development of sensor and actuator arrangements that are able to approximately perform independent modal state control, greatly improving the realization of a more efficient and robust closed-loop aeroelastic system. Smart materials have been under-utilized in the aerospace community because of reliability issues. This ground test provided an opportunity to evaluate piezoelectric actuators in resolving a vibration problem on an aerospace vehicle.

\section{Control Synthesis}

The objective of the present work was to develop a control system using strain actuation to attenuate the dynamic response caused by buffet loads. Figure 1 shows the schematics of the closed-loop, output feedback control system analyzed. The buffeting pressure acting on the fin was treated as a disturbance of stochastic nature. The other input vector was due to the action of the two actuator groups which were patched to the structure to reproduce as closely as possible the strain distribution associated with each one 
of the first two aeroelastic modes. Hence, each group had more control authority over one specific mode of the structure. Two vectors defined the system output: the first collected the signal produced by the sensor monitored for performance (normally the strain gauge located at the critical point for fatigue at the fin root), and the second the signal originated from the two sensors used for the feedback control.

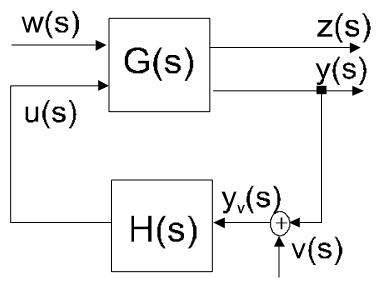

Figure 1: Output Feedback Active Control System (Disturbance Rejection).

The frequency-domain transfer function representation of the MIMO system presented in Fig. 1 is:

$$
\left\{\begin{array}{c}
y_{V}(s) \\
z(s)
\end{array}\right\}=\left[\begin{array}{ll}
G_{11}(s) & G_{12}(s) \\
G_{21}(s) & G_{22}(s)
\end{array}\right]\left\{\begin{array}{l}
u(s) \\
w(s)
\end{array}\right\}
$$

The disturbance load was applied at a single point of the structure - the shaker position defined in the ground tests.

For the open-loop case, Eq. 1 gives:

$$
z(s)=G_{22}(s) w(s)
$$

Referring to Fig. 1:

$$
u(s)=H(s) y_{v}(s)
$$

Substitution of Eq. 3 into the first row of Eq. 1 yields:

$$
y_{\mathcal{V}}(s)=\left(1-G_{11}(s) H(s)\right)^{-1} G_{12}(s) w(s)
$$

Using Eq. 3 again:

$$
u(s)=H(s)\left(1-G_{11}(s) H(s)\right)^{-1} G_{12}(s) w(s)
$$

Finally, using the second row of Eq. 1, it follows that:

$$
\begin{array}{r}
\mathrm{z}(\mathrm{s})=\left(G_{11}(s) H(s)\left(1-G_{11}(s) H(s)\right)^{-1} G_{12}(s)+\right. \\
\left.G_{22}(s)\right) w(s)
\end{array}
$$

that gives for the control signal:

$$
u(s)=G_{u}(s) w(s)
$$

In the present work, the buffet conditions presented in Table 1 were represented.

Table 1: Buffet Conditions

\begin{tabular}{ccc}
\hline \hline $\begin{array}{c}\text { flight condition } \\
\text { number }\end{array}$ & $\begin{array}{c}\text { angle of } \\
\text { attack } \\
\text { (degrees) }\end{array}$ & $\begin{array}{c}\text { dynamic } \\
\text { pressure } \\
\text { (psf) }\end{array}$ \\
\hline FC1 & $12-16$ & $225-300$ \\
FC3 & $20-24$ & $225-300$ \\
FC5 $^{(1)}$ & $28-32$ & $300-350$ \\
FC6 $^{(2)}$ & $28-32$ & $300-350$ \\
\hline (1) $50 \%$ of maximum power to shaker \\
(2) $100 \%$ of maximum power to shaker
\end{tabular}

\section{System Identification}

During the open-loop tests in September 1997, the standard technique of measuring system transfer functions by energizing each drive system (shaker and actuator groups) independently and measuring the sensor response provided unexpected results. These were ascribed to the internal damping of the large electrodynamic shaker changing the stiffness of the fin when not energized (a node was artificially forced at the shaker attachment point). Unfortunately, the magnitude of this damping was large compared to the singular effect of each actuator string thereby effectively masking the true transfer function. A solution to this problem was found by feeding all three input variables (actuator groups G1 and G2 and the buffet disturbance) using three simultaneous and independent random processes. However, this procedure slowed down the convergence of the transfer functions due to the increasing importance of the cross talk amongst drivers and transducers. Due to the fact that the shaker controller could only run relatively short time sequences, an unsatisfactory number of ensembles could be taken to determine the individual transfer functions. Therefore, optimization techniques were then required, obtaining the "best" estimate of the required transfer functions in a least square sense in terms of the cross- and power-spectral-densities measured between a given input and the correspondent output. For every transducer three transfer functions were found corresponding to the two controls and the one load reference signal. From these estimates of the various transfer functions, system identification routines were either written or existing programs were used to determine pole-zero and state-space models. Determining a state-space model of the plant represents the first and essential step in designing the controller, especially for a system of any complexity. 


\section{Performance Calculations}

The power spectral density (PSD) of the disturbance was a known input obtained from the flight tests. Due to hardware limitations, these PSD's were band-limited. The frequency content lying outside of each one of the critical modes for buffeting was cut off. Furthermore, in the ground test, this PSD described the shaker input signal that excited the structure at a single point. Also, between the shaker and the structure there was a load cell. The PSD of the output of this load cell was assumed to correspond to the disturbance load applied to the fin to simulate buffeting. The subsequent use of the product between Eqs. 2, 5 and 7 and their respective complex conjugates produced the PSD's of the performance sensors in the open- and closed-loop cases, and the control signal, respectively:

$$
P S D_{\text {output }}=\mid \text { Transfer Function }\left.\right|^{2} P S D_{\text {input }}
$$

From these PSD's, both the control effort RMS values of each actuator group (as a fraction of the maximum allowed by the hardware), and the ratio (closed- over open-loop) of the RMS values of the performance sensors were obtained. These were the metrics used to evaluate the performance.

\section{Experimental Set-up}

The IFOSTP rig in Australia was used for the ground test of the full-scale aircraft (Fig. 2). The piezoelectric actuation devices were attached to both sides of the starboard vertical fin (Fig. 3). Two banks of amplifiers drove the two groups of actuators acting in opposite phase at each side of the fin to generate bending. The amplifiers fed the maximum voltage differential allowed across the piezoelectric devices (approximately $1500 \mathrm{~V}$ peak-to-peak). The third input signal was given by the $5000 \mathrm{lbf}$ electromagnetic shaker attached to a single point at center of the starboard side of the fin through a load cell. Representative buffet time sequences associated with the chosen flight conditions were fed into the computer that controlled the shaker. A load cell was placed between the shaker and the structure to monitor the actual dynamic loads transmitted into the structure by the exciting mechanism.

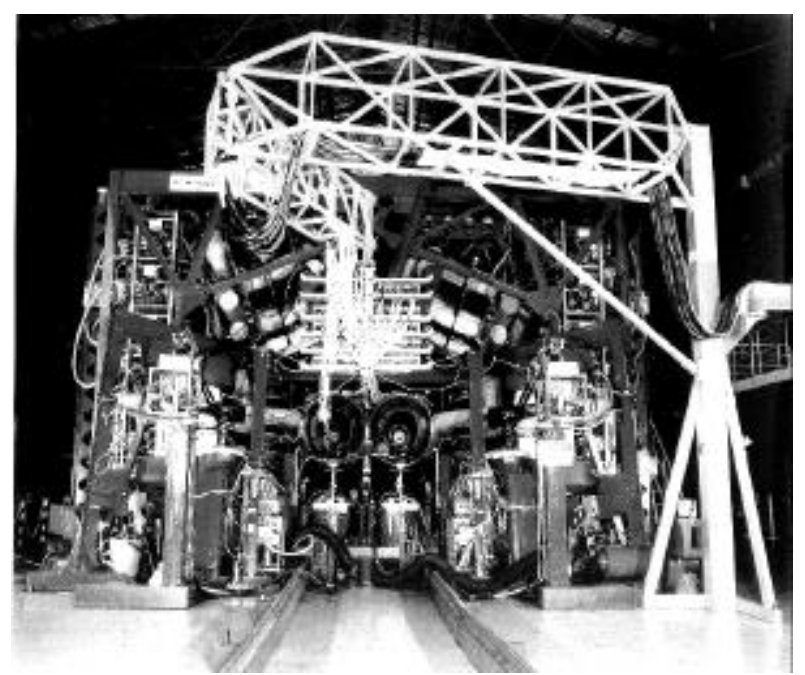

Figure 2: Full-Scaled Aircraft in the Australian IFOSTP Rig.

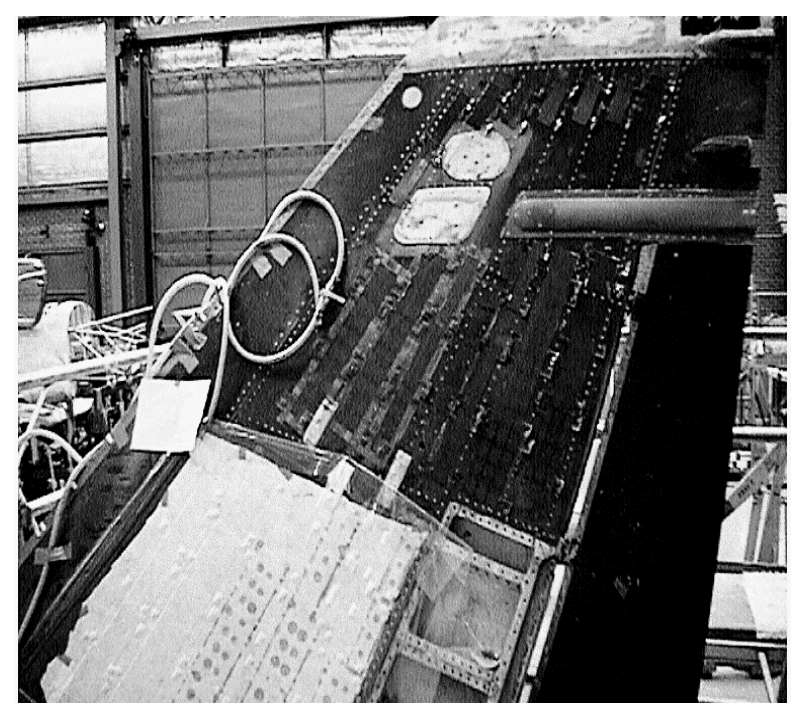

Figure 3: Instrumented Vertical Fin.

In light of the additional damping caused by the shaker, air bags which are customarily inflated to simulate the aerodynamic damping provided by the motiondependent air loads were deflated for the ground test.

Four accelerometers and six strain gauge rosettes situated at strategic points of the fin provided the output signals. 
In the control room, an 8-channel data acquisition system was used to acquire real-time frequency-domain data including transfer functions and auto-spectra. In addition, a 16-channel digital tape recorder was used to record data from all available signals for subsequent off-line analyses. The signal from two channels could be selected for feedback control through a computer driven DSP (digital signal processing) board.

\section{$\underline{\text { Parametric Study Involving Sensors }}$}

\section{$\underline{\text { Rationale }}$}

In order to study the effect that the choice of sensors (strain gauges and/or accelerometers) and sensor location has on the overall performance of the active control system, a parametric study was conducted. It was expected that strain gauges having direct correlation with the system performance metrics would provide better performance. Therefore, three control laws (CL1, CL2 and CL3) were designed based on open-loop test data using the feedback from different pairs of sensors. The identification of the sensors used and their respective participation in a determined control law is summarized in Table 2.

The typical regulator was designed for performance in the bandwidth defined by 10 and $60 \mathrm{~Hz}$, with roll-off at the lower and higher frequencies. The Separation Theorem of the classic LQE-LQR Optimal Control theory was used to obtain the Kalman filter and the fullstate feedback gains. Emphasis in the control law synthesis was given to attenuate the dynamic response associated with both the first and second natural modes of the vertical fin. All control laws were designed based on open-loop test data for FC1.

A band-pass filter was appended in-series to the controller output in some designs to cut either a DC signal (when strain is used for feedback) or an undesirable high-frequency response (to guarantee stability).
Table 2: Feedback Control Synthesis

\begin{tabular}{ccc}
\hline \hline $\begin{array}{c}\text { sensor } \\
\text { identification }\end{array}$ & $\begin{array}{c}\text { approximate sensor } \\
\text { position }\end{array}$ & $\begin{array}{c}\text { control law } \\
\text { identification }\end{array}$ \\
\hline A1 & $\begin{array}{c}\text { fin tip, near leading } \\
\text { edge }\end{array}$ & CL1 \\
A2 & $\begin{array}{c}\text { edge } \\
\text { fin tip, near trailing } \\
\text { edge } \\
\text { A3 }\end{array}$ & CL1 \& CL2 \\
& $\begin{array}{c}\text { l/3-span, near } \\
\text { leading edge } \\
\text { 1/3-span, near } \\
\text { rudder leading } \\
\text { edge } \\
\text { Ain root, near } \\
\text { rudder leading } \\
\text { edge (critical point) } \\
\text { 2/3-span, near } \\
\text { rudder leading } \\
\text { edge }\end{array}$ & none \\
SG3 & none CL3 \\
& CL3 \\
SG5 & & \\
\hline \hline
\end{tabular}

Note: "A" defines accelerometer and "SG" strain gauge.

Experimental Results

Table 3 depicts the control performance in the frequency intervals shown. The given bands include modes 1,2 , and 1 and 2 together, respectively. In the Table, the results for two selected performance metrics are listed: accelerometer A2 and strain gauge SG3. From the sensor locations, one can observe that strain gauge SG3 represented a good measurement of mode 1 , whereas accelerometer $\mathrm{A} 2$ was more related to mode 2. All the three control laws studied presented reduction in the vibration levels associated with mode 1 less significant than those obtained for mode 2 . The best results were obtained when the signal form strain gauge SG3 was used in the feedback loop, as in case of control laws CL2 and CL3, confirming the initial predictions. It is worthwhile to point out that control law CL1 was in the case of flight condition FC1 limited in gain to guarantee the controller stability.

Table 3: Parametric Study involving Sensors. Experimental Results. Closed over Open Loop RMS values (\%).

\begin{tabular}{|c|c|c|c|c|c|c|c|}
\hline \hline \multirow{2}{*}{$\begin{array}{c}\text { Flight } \\
\text { Condition }\end{array}$} & $\begin{array}{c}\text { Frequency band } \\
(\mathrm{Hz})\end{array}$ & \multicolumn{2}{|c|}{ CL1 } & \multicolumn{3}{|c|}{ CL2 } & \multicolumn{2}{c|}{ CL3 } \\
\cline { 2 - 8 } & A2 & SG3 & A2 & SG3 & A2 & SG3 \\
\hline \hline \multirow{3}{*}{ FC1 } & $5-25$ & 97.1 & 99.7 & 70.3 & 69.4 & 64.8 & 70.0 \\
\cline { 2 - 8 } & $25-100$ & 82.6 & 92.6 & 57.8 & 42.5 & 84.9 & 67.2 \\
\cline { 2 - 8 } & $5-100$ & 83.3 & 98.8 & 58.5 & 66.7 & 84.9 & 69.6 \\
\hline \multirow{4}{*}{ FC3 } & $5-25$ & 97.0 & 98.0 & 93.3 & 91.7 & 92.4 & 93.0 \\
\cline { 2 - 8 } & $25-100$ & 81.8 & 90.0 & 86.9 & 82.0 & 94.1 & 87.6 \\
\cline { 2 - 8 } & $5-100$ & 83.1 & 97.6 & 87.3 & 91.3 & 93.9 & 92.8 \\
\hline \multirow{3}{*}{ FC5 } & $5-25$ & 98.0 & 98.0 & 92.3 & 91.7 & 93.0 & 92.6 \\
\cline { 2 - 8 } & $25-100$ & 88.0 & 95.3 & 86.9 & 82.0 & 98.2 & 92.4 \\
\cline { 2 - 8 } & $5-100$ & 88.3 & 97.7 & 87.3 & 91.3 & 98.0 & 92.6 \\
\hline \hline
\end{tabular}


Several attempts at a closed-loop run of a MIMO controller during flight condition FC6 were unsuccessful. During each attempt, an actuator on the upper group failed resulting in a system automatic shutdown. Therefore, a SISO (single-input-singleoutput) controller was designed for commanding only the lower group of actuators to reduce buffeting in the first bending mode of the tail during a closed-loop run at FC6. Using feedback from accelerometer A2 and a nominal gain setting to increase chances of success, this SISO controller reduced the RMS strain at gauge SG3 by approximately $3 \%$ between the frequency range of $10-20 \mathrm{~Hz}$. Between $0-100 \mathrm{~Hz}$, the RMS strain at gauge SG3 was reduced by approximately $2.5 \%$. Further testing at FC6 was not considered after this successful run.

However, FC5 and FC6 were identical flight conditions except that shaker power was limited to $50 \%$ of the power for FC6. Table 3 suggests that better reductions of maximum strains would be achieved with the MIMO approach at full actuator power compared to the SISO approach, thereby establishing a lower limit on performance.

Estimates from Boeing indicate that a $10 \%$ reduction in the maximum strain at the fin root doubles the fatigue life of the structure.

\section{$\underline{\text { Conclusions }}$}

The test represents an important step in the development of adaptive "smart" structures systems. A full-scale aircraft instrumented to reduce buffet loads using this new technology was tested.

Very promising results were obtained in parametric studies using different sensors in a two-input, twooutput controller using a standard linear time invariant LQG design. Vertical fin buffet attenuation exceeding $60 \%$ for the nominal flight configuration $\mathrm{FC} 1$ and $30 \%$ for the most severe case FC5 was observed during the tests. Also, very significant vibration reduction measured by the most important performance metric the strain gauge located at the critical point for fatigue (SG3) was verified for FC5: 18\% (Mode 2) and 8.7\% (Modes 1 and 2). In general, the control laws that included at least one strain gauge in the feedback loop revealed better performance. In fact, CL2 comprising feedback from one accelerometer situated at the tip of the fin and SG3 presented the best results. This is an indication that strain gauges can be better co-related to the control objective, which is to reduce the structural strain generated by buffeting.

\section{$\underline{\text { References }}$}

1. Zimmerman, N. H., Ferman, M. A., Yurkovich, R. N. and Gerstenkorn, G., "Prediction of Tail Buffet Loads for Design Application," AIAA/ASME/ASCE/ AHS/ASC 30th Structures, Structural Dynamics and Materials Conference, American Institute of Aeronautics and Astronautics, Washington, DC, pp. 1911-1919.

2. Ferman, M. A., Patel, S. R., Zimmerman, N. H. and Gerstenkorn, G., "A Unified Approach to Buffet Response of Fighter Aircraft Empennage," Aircraft Dynamic Loads due to Flow Separation, AGARD Report CP-483, North Atlantic Treaty Organization, Neuilly-Sur-Seine, France, September 1990, pp. 2.1-2.18.

3. Lee, B. H. K., Brown, D., Zgela, M. and Poirel, D., "Wind Tunnel and Flight Tests of Tail Buffet on the CF-18 Aircraft," Aircraft Dynamic Loads due to Flow Separation, AGARD Report CP-483, North Atlantic Treaty Organization, Neuilly-Sur-Seine, France, September 1990, pp. 1.1-1.26.

4. Edwards, J. W., "Unsteady Airloads Due to Separated Flow on Airfoils and Wings," Aircraft Dynamic Loads due to Flow Separation, AGARD Report CP-483, North Atlantic Treaty Organization, Neuilly-Sur-Seine, France, September 1990, pp. 16.1-16.18.

5. Rock, S. M., Ashley, H., Digumarthi, R. and Chaney, K., "Active Control for Fin Buffet Alleviation," in Advances in Aerospace Sciences: A Tribute to Prof. Holt Ashley, P. Hagela and S. C. McIntosh, Jr. Editors, Stanford University, 1993, pp. 413-421.

6. Nitzsche, F., Zimcik, D. G. and Langille, K. “Active Control of Vertical Fin Buffeting with Aerodynamic Control Surface and Strain Actuation," AIAA/ASME/AHS Adaptive Structures Forum, Kissimmee, FL, April 7-10, 1997, American Institute of Aeronautics and Astronautics, Washington DC, CP973, pp. 1467-1477.

7. Moses, R. W., "Vertical fin buffeting alleviation using piezoelectric actuators," in Smart Structures and Materials 1997, Industrial and Commercial Applications of Smart Structures Technologies, J. M. Sater, Ed., SPIE Vol. 3044.

8. Hopkins, M., Henderson, D., Moses, R., Ryall, T., Zimcik, D., Spangler, R., "Active Vibration Suppression Systems Applied to Twin Tail Buffeting," Proceedings: SPIE 5th Annual International Symposium on Smart Structures and Materials, SPIE Paper No. 3326-05, 1998. 